\title{
Properties of an aquatic micro-ecosystem
}

\author{
II. Steady-state phenomena in the autotrophic subsystem
}

\author{
J. RINGELBERG \\ Laboratory of Limnology, University of Amsterdam; Amsterdam, The Netherlands
}

\begin{abstract}
A micro-ecosystem, composed of three trophic levels, was built in 1973. Up to the present time (1976) the biological and chemical state has remained essentially the same. The trophic levels are spatially separated, but interconnected by a continuous flow system. Especially steady state properties of the autotrophic subsystem are discussed. The herbivorous subsystem, mainly populated by Daphnia magna, has a population density of 400-700 individuals per liter, though strong fluctuations can be observed. The composition of the decomposer unit is unknown. A high rate of mineralization and a high buffering capacity, at least for phosphor, are present. This results in a constant output rate of phosphor over long periods. The autotrophic subsystem contains different species of algae, although at most times one or two are dominating. The algal biomass fluctuates around a mean concentration of $1.6 \times 10^{10} \mu \mathrm{m}^{3} \mathrm{1}^{-1}$. A "statistical steady state" is present with a mean relative rate of change in total particle volume equal to the dilution rate. The kind of frequency distribution of the relative rate of change seems to depend to a large extent on the conditions of the system. An autocorrelation technique was used to analyse the particle volume time series for periodic oscillations. For stationary periods a periodic function is involved which might be independent of the algal association present. The micro-ecosystem shows a strong tendency for selfmaintenance. It seems to be suitable for long-term observations and for experimentation with various ecosystem properties. It is especially suited for studying the behaviour of toxic substances in the foodweb, as well as the fate of these toxicants after mineralization and reentering of the foodchain.
\end{abstract}

\section{INTRODUCTION}

Compared to other branches of biology, ecosystem research especially is seriously hampered by the near impossibility of doing experiments. The objective of building microsystems is to provide tools for (a) doing observations under less variable environmental circumstances, and (b) doing experiments to test hypotheses. Especially in aquatic ecology, microsystems have been built more or less successfully (see review by Taub, 1974, and discussion in Ringelberg \& Kersting, in press).

To fulfil their purpose, microsystems must be of a certain realistic nature. The vagueness of this statement reflects that it depends on the kind of study in view whether a system is realistic or not. Most certainly, microsystems must have long lifetimes because phenomena on the ecosystem level of integration have long response times compared, for instance, to those in physiology. With regard to experimentation the state of the system must be sufficiently known in order to be able to observe an 
experimentally induced change. The best one can hope for is a steady state of the property that is of interest.

The objective of this paper is to discuss steady state properties of an autotrophic subsystem. This subsystem is part of a microsystem consisting of three "trophic levels": autotrophs (algae), herbivores (Daphnia) and decomposers (systematically unknown). To a large extent these types of organisms are separated in different aquaria (Fig. 1). Because of a circulatory flow system the levels are mutually dependent. The argumen-

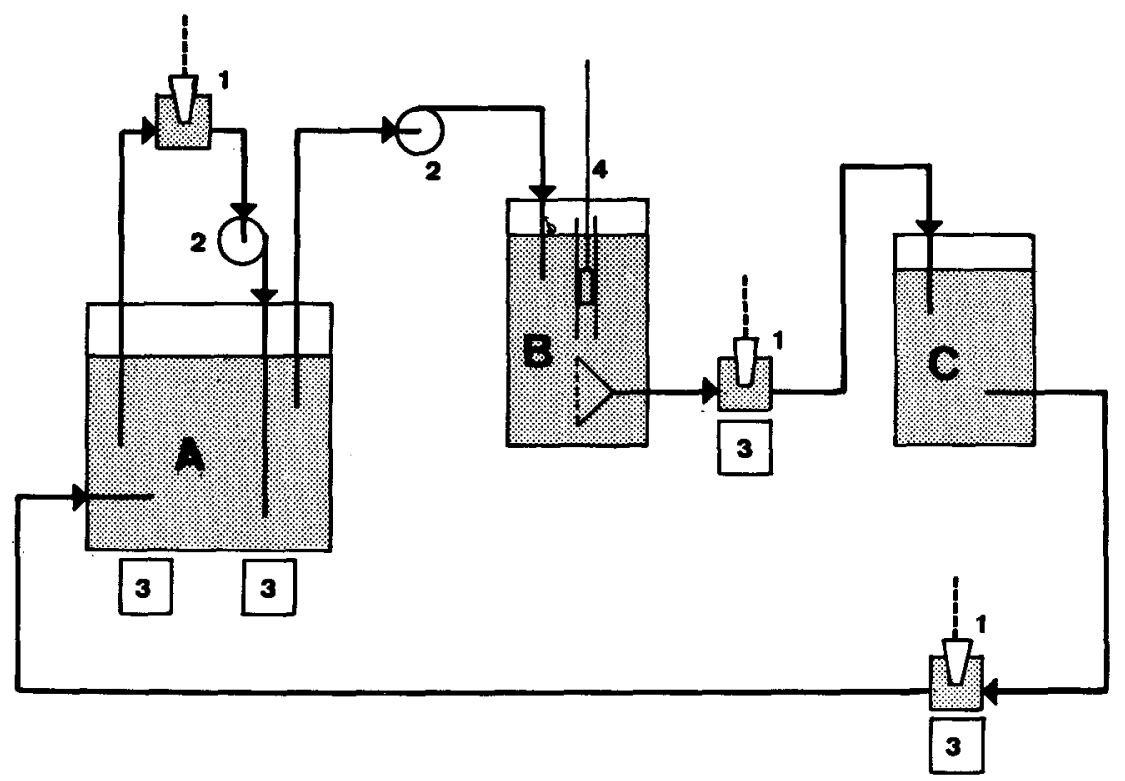

Fig. 1: Schematic presentation of the micro-ecosystem. $\mathrm{A}=$ autotrophic unit; $\mathrm{B}=$ herbivorous unit; $\mathrm{C}=$ decomposer unit; $1=$ oxygen probe; $2=$ pump; $3=$ magnetic stirrer; $4=$ mixing device

tation for this kind of design is given in extenso by Ringelberg \& Kersting (in press). Prototypes were started in Spring 1973 and are in operation still. An extensive observation program started at the end of that year (day 180), at the closing of a period of technical alterations. The long lifetime is a. o. due to the presence of sufficient mineralization and recirculation of nutrients. The dimensions and some other characteristics of the prototype under discussion are given in Table 1.

The subsystem was seeded with Cblorella vulgaris and Scenedesmus quadricauda. Infection proved to be easy, however, and on day 180 the algal association was composed of about seven species. Dominance changed, Oscillatoria cf. subtilissima and Fragillaria construens being the most abundant species during the first bloom but the second was dominated by Oscillatoria and Scenedesmus abundans. In between Cryptomonas erosa was the most common species. From day 280 until day 765 Oscillatoria made up most of the biomass but from that day onwards it was replaced by Kirchneriella obesa. Biomass was estimated as total volume of particles larger than $30 \mu \mathrm{m}^{3}$. 
Table 1

Characteristics of the micro-ecosystem

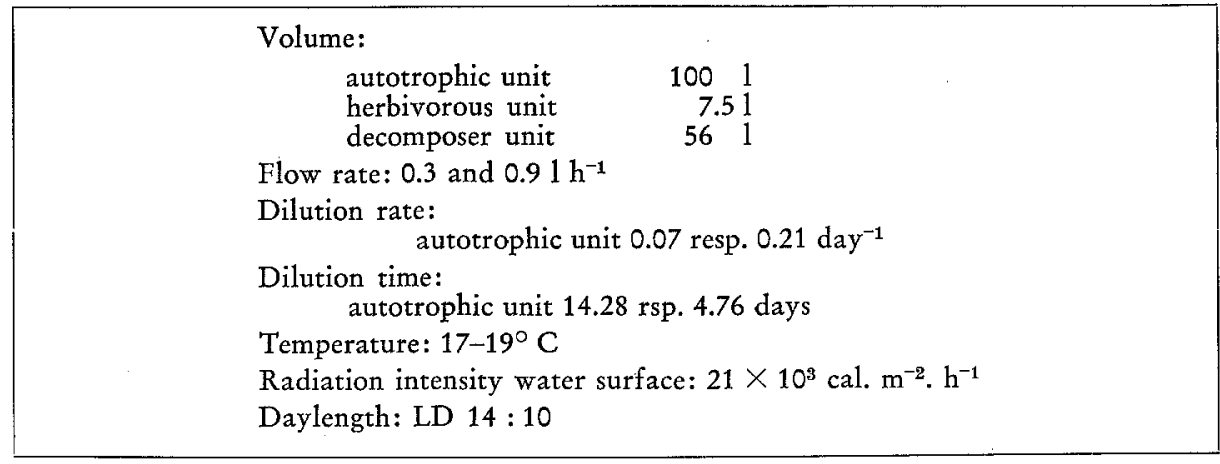

At least twice a week, but more often daily determinations were made using a Coulter Counter Model ZB with C 1000 Channelyzer. Input from the decomposer unit of particles exceeding this size was nil. Detritus was negligible. The flow velocity was changed twice as indicated in Figure $2 \mathrm{~A}, \mathrm{~B}$ and in Table 1.

\section{RESULTS AND CONCLUSIONS}

(1) The algal biomass is presented in Figure $2 \mathrm{~A}$ and $\mathrm{B}$ as Napierian logarithms against time. These time series were checked for trends. Cumulative means were calculated backwards from day 518 to day 187,680 to 518 and 987 to 682 . Cumulative means were constant for the days 518-264 (Period I), 680-610 (Period II) and 989 to 824 (Period III) (observation 1.1). An additional indication for a stationary signal during these periods will be found under 2 .

For the stationary phases the frequencies of the total volume classes are more evenly distributed than expected in the case of a normal distribution (1.2). Therefore, a nonparametric test was used to test the hypothesis that the particle volumes of these stationary periods come from statistical populations having the same distributions (Wilcoxon's two-sample test, Sokal \& Rohlf, 1969). From Table 2 it can be read that the particle volumes of Periods I and II and I and III are the same but that for II and III the hypothesis has to be rejected (1.3). The length of Period II is rather short and conclusions with regard to this period must be of a preliminary nature. For Period I and III the algal biomass seems to fluctuate around the same mean level. The flow velocity was the same during these periods but the biomass was made up from different species (1.4).

From observations 1.1, 1.3 and 1.4 the hypothesis is formulated that in the microecosystem (MES) algae grow to a certain particle volume biomass which is independent of the species composition of the association but determined by a system's property, the "carrying capacity".

The signal of the Periods $187-264,518-610$ and $680-824$ is transient as a result 
of a change in the system's condition. The nature of the first change is unknown. The long transient times are pointed out (1.5).

(2) In the absence of a trend in biomass concentration (1.1) the mean relative rate of change in total particle volume must be equal to the dilution rate $D$ of the
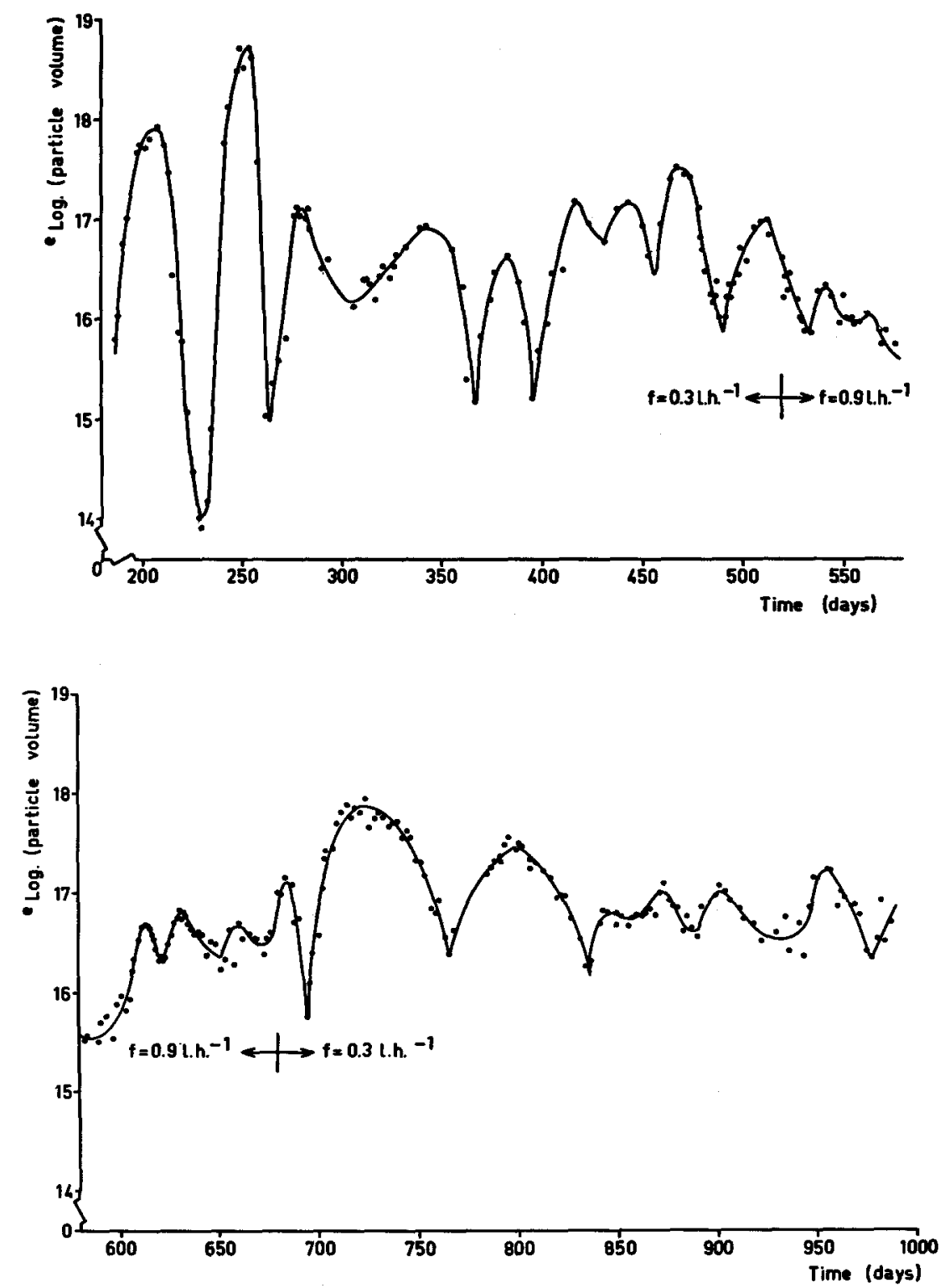

Fig. 2: Total particle volume in the autotrophic subsystem as estimated by the Coulter Counter. Changes in flow velocity $f$ are indicated 
Table 2

Comparison of total particle volumes

\begin{tabular}{|ccccc|}
\hline \multicolumn{2}{c}{ Period } & $\mathrm{n}$ & $\overline{\log _{\mathrm{e}} \mathrm{X}(\mathrm{t})}$ & $s$ \\
\hline I. & $264-514$ & 73 & 16.61 & 0.55 \\
II. & $610-680$ & 45 & 16.56 & 0.15 \\
III. $824-989$ & 60 & 16.74 & 0.23 \\
\hline
\end{tabular}

Wilcoxon test parameter values and probabilities

\begin{tabular}{|cll|}
\hline & \multicolumn{1}{c|}{ II } & \multicolumn{1}{c|}{ III } \\
\hline I & $\mathrm{t}=0.525$ & $\mathrm{t}=0.878$ \\
& $\mathrm{P}>0.5$ & $\mathrm{P}=0.4$ \\
II & & $\mathrm{t}=4.02$ \\
& & $\mathrm{P}<0.001$ \\
\hline
\end{tabular}

autotrophic unit. This relative rate of change was calculated according to the formula

$$
v=\frac{\ln \mathrm{x}(\mathrm{t}+\Delta \mathrm{t})-\ln \mathrm{x}(\mathrm{t})}{\Delta \mathrm{t}}+\mathrm{D}
$$

For the Periods I, II and III the mean relative rate of change equals the dilution rate (see Table 3) (2.1). It is concluded that the autotrophic subsystem is in a "statistical steady state" during these periods. Some suggestions on the stochastic nature of the relative rate of change can be read from Figure 3. In this figure the frequencies of these rates are given as cumulative percentages. The three distributions I, II and III look like leptokurtic curves (Sokal \& Rohlf, 1969) with relative high numbers near the mean and the tails. Especially the lower end tail, up to the zero value, contains relative high numbers. It seems these curves are built up from more than one frequency distribution indicating different population processes (2.2). The negative rates of change mean, for instance, dying cells since they follow a yellowing of the algae and a decrease in oxygen production (photosynthesis). However, the rate values might not be considered actual dying and lysis rates since only suspended particles were counted. In part, the decreases might be ascribed to higher sinking rates.

Table 3

Characteristics of the relative rate of change in total particle volume

\begin{tabular}{ccccc|}
\hline Period & $\begin{array}{c}\bar{v} \\
\left(\text { day }^{-1}\right)\end{array}$ & $s$ & $\mathrm{n}$ & $\begin{array}{c}\mathrm{D} \\
\left(\text { day }^{-1}\right)\end{array}$ \\
\hline I & 0.078 & 0.142 & 74 & 0.07 \\
II & 0.214 & 0.083 & 44 & 0.21 \\
III & 0.079 & 0.096 & 59 & 0.07 \\
\hline
\end{tabular}


The "statistical steady state" is the result of the particular combination of frequencies (2.3). At least two parameters are necessary to describe a "statistical steady state", the mean value and the variance. This fact is mentioned to point to the steady states of chemostats where $\mu=\mathrm{D}$ is the only (deterministic) parameter necessary.

A change in flow rate results in a shift of the whole distribution (Curve I to II). In this case Oscillatoria cf. subtilissima remained the dominant species. The mor-

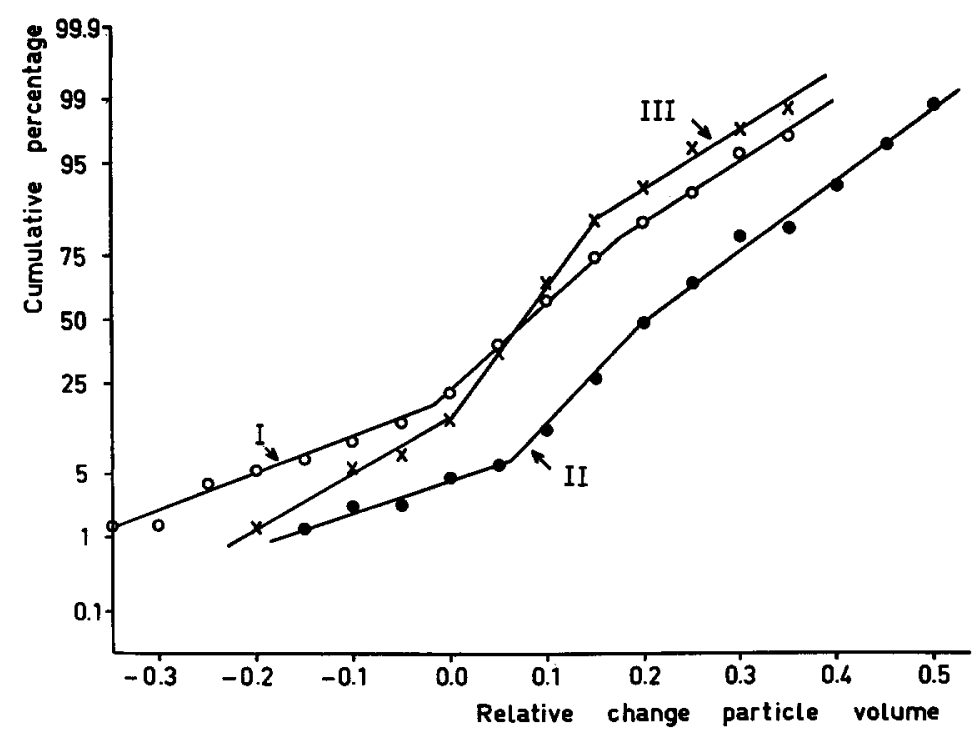

Fig. 3: The cumulative percentages of the relative changes in total particle volume on probability paper. The different curves hold for the three Stationary periods I, II and III mentioned in the text

phology changed, however, with the trichomes getting thinner. A change back to the original flow rate was followed by a change in species dominance. On day $765 \mathrm{Kirch}-$ neriella obesa has almost completely replaced Oscillatoria (2.4). The frequency distributions I and III are almost entirely the same, however (2.5). From the observations 2.1, 2.3, 2.4 and 2.5 the hypothesis is formulated that the character of the relative change in particle volume is to a large extent determined by the properties of the MES.

(3) The particle volume time series were analysed for periodic oscillations. An autocorrelation technique was used (Van der Grinten \& Lenoir, 1973); Vandeginste et al., 1976). The autocorrelation function

$$
\psi_{\mathrm{ww}}(\tau)=(\mathrm{N}-\mathrm{n})^{-1} \sum_{\mathrm{t}=\mathrm{o}}^{\mathrm{t}=(\mathrm{N}-\mathrm{n}) \Lambda \mathrm{t}} \mathrm{w}(\mathrm{t}) \cdot \mathrm{w}(\mathrm{t}+\tau)
$$

was normalized, dividing $\psi_{\mathrm{ww}}(\tau)$ by $\psi_{\mathrm{ww}}(\mathrm{o})=\psi_{\mathrm{ww}}(\tau)$ for $\mathrm{n}=\mathrm{o}$. 
The autocovariance function is

$$
\Phi_{\mathrm{wW}}(\tau)=\psi_{\mathrm{ww}} / \psi_{\mathrm{wW}}(\mathrm{o})
$$

$w(t)=\log _{e} x(t)-\overline{\log _{e} x} ; \log _{e} x(t)$ read from the smoothed curve for time intervals of $\Delta \mathrm{t}=3$ days.

$\mathrm{N}=$ total number of items $\mathbf{w}(\mathrm{t})$.

$\mathrm{n}=$ number of time shifts.

$\tau=\mathrm{nx} \Delta \mathrm{t}$, the amount of the time shift.

To test for a significant departure of $\Phi_{\mathrm{ww}}(\tau)$ from zero, a Student t-testing was used (df $=\mathrm{N}-\mathrm{n}-1, \mathrm{P}=0.01)$. The variance of $\Phi_{\mathrm{ww}}(\tau)$ was calculated according to

$$
\begin{aligned}
& \operatorname{Var}\left(\Phi_{\mathrm{ww}}(\tau, \mathrm{n} \Delta \mathrm{t})=\frac{1}{\mathrm{~N} \Delta \mathrm{t}}(2 \mathrm{~N}+1) \Phi_{\mathrm{ww}}^{2}(\tau)+\right. \\
& \begin{aligned}
\mathrm{n}=\mathrm{N} \\
\quad+\sum_{\mathrm{n}=\mathrm{o}}
\end{aligned}
\end{aligned}
$$

Autocovariances were calculated for the Stationary periods I, II and III. The autocorrelograms are presented in Figure 4 A, B and C.

The correlograms for Period I and III do not damp down. The autocovariance values of the peaks differ from zero with a reliability better than $99 \%$ (Table 4 ). Moreover the oscillations are rather consistent. The cycles of Period I $(\tau=14.9)$ and of Period II $(\tau=14.5)$ are comparable (3.1). It is suggested that a periodic function is involved with an oscillation time of $\mathrm{T}=44$ days.

Observation period II is rather short. Though the peak values are significant there is a tendency to become gradually lower. No conclusion seems to be permitted on this too short series.

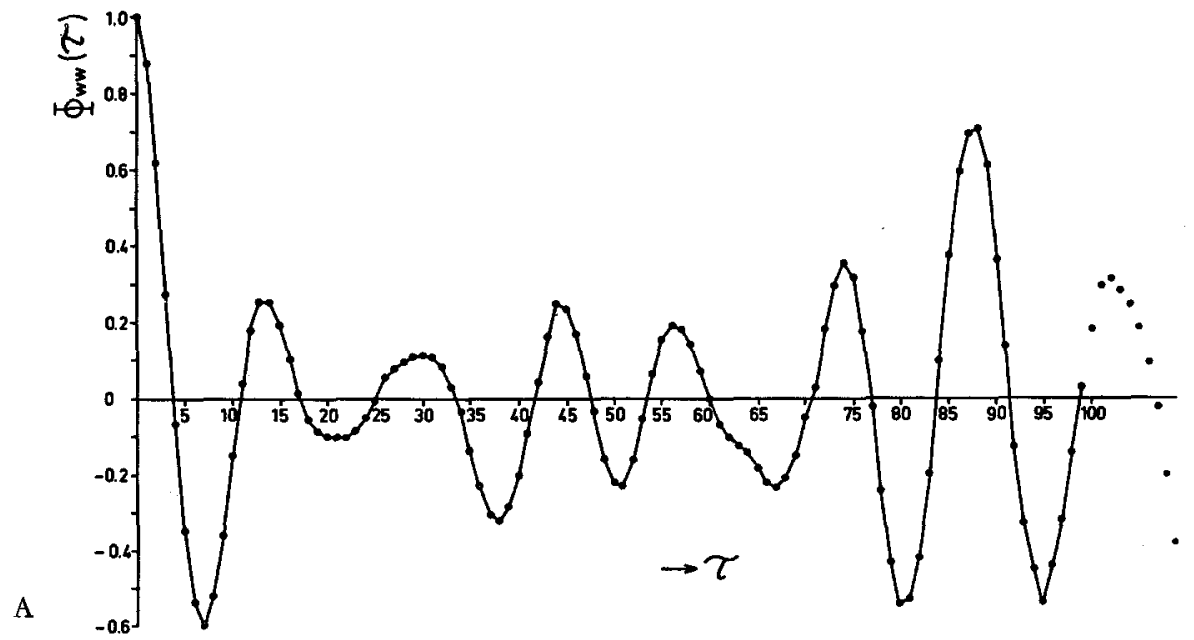

Fig. 4: (A) The autocorrelogram of the total particle volume during Stationary period I. (B) Idem for Stationary period II. (C) Idem for Stationary period III 


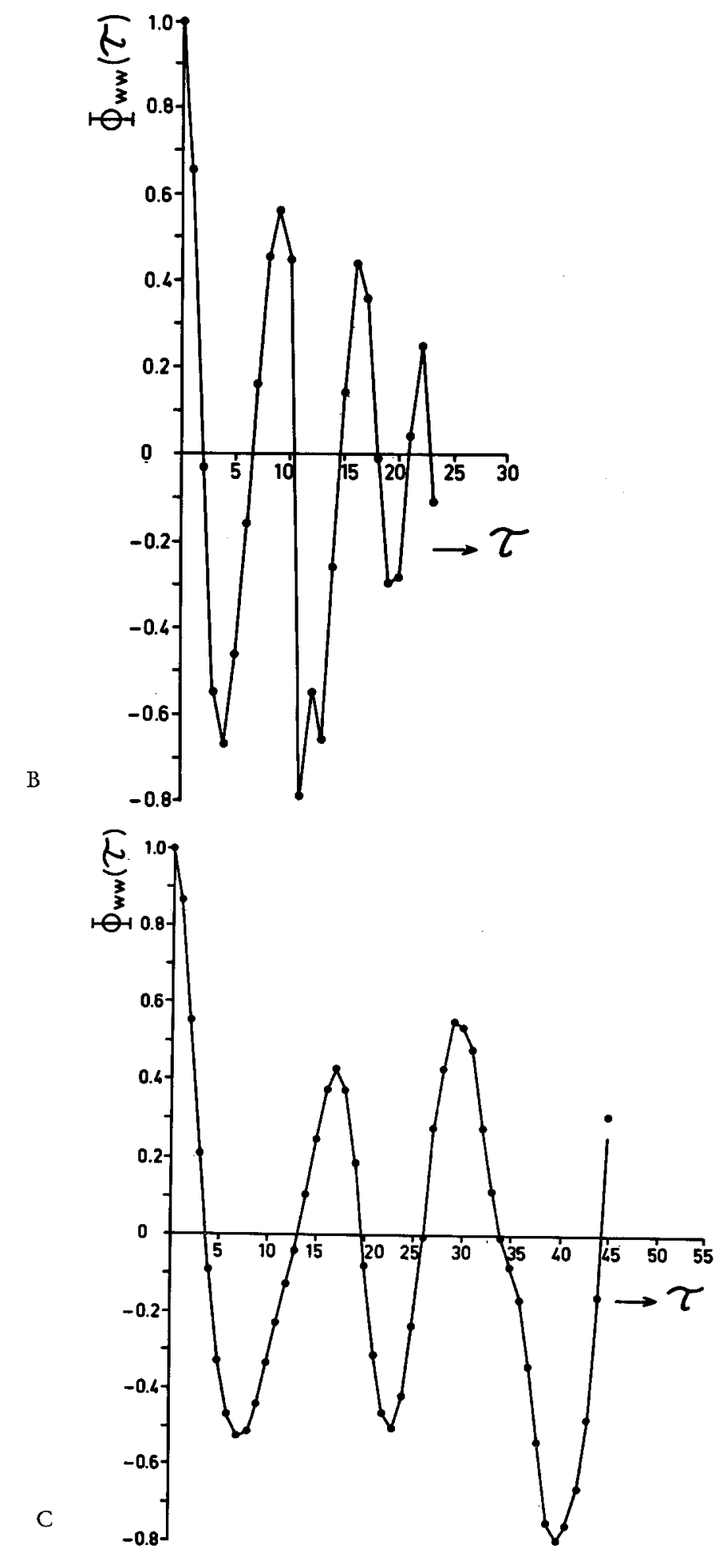


Table 4

Results of the autocorrelation

\begin{tabular}{|c|c|c|c|}
\hline & Autocovariance & Variance & $\begin{array}{c}\text { Significance } \\
\text { level at } 99 \%\end{array}$ \\
\hline$\Phi \mathrm{WW}$ & $\begin{array}{l}d I \\
(14)=0.255 \\
(30)=0.117 \\
(44)=0.250 \\
(74)=0.363\end{array}$ & $\begin{array}{l}0.047 \\
0.011 \\
0.025 \\
0.063\end{array}$ & $\begin{array}{l}0.052 \\
0.028 \\
0.047 \\
0.103\end{array}$ \\
\hline$\Phi$ ww & $\begin{aligned} d \text { II } & \\
(9) & =0.564 \\
(16) & =0.441\end{aligned}$ & $\begin{array}{l}0.143 \\
0.014\end{array}$ & $\begin{array}{l}0.254 \\
0.124\end{array}$ \\
\hline$\Phi_{\mathrm{WW}}$ & $\begin{array}{l}d \text { III } \\
(17)=0.433 \\
(29)=0.547\end{array}$ & $\begin{array}{l}0.102 \\
0.118\end{array}$ & $\begin{array}{l}0.131 \\
0.175\end{array}$ \\
\hline
\end{tabular}

\section{FINAL REMARKS}

The micro-ecosystem of which the autotrophic subsystem is discussed has a lifetime of years. This makes long term studies possible. The biomass of the algae grows into a "statistical steady state", probably of a certain concentration typical for the state of the MES, for instance, but independent of the species composition. A technical feature, like the flow velocity, has (within limits, certainly) no influence on this biomass concentration. This facilitates experimentation. The time needed to reach a steady state value is long, however. A threefold increase in flow rate resulted in a transient period of about 100 days. A change back to the original flow rate resulted in a transient period of about 144 days. These are very long response times compared to physiology, however realistic in ecology. A remarkable phenomenon is the presence of an oscillation with a comparable period for at least two different algal associations, dominated by such unrelated species as Oscillatoria subtilissima and Kirchneriella obesa. The nature of this oscillation is unknown. It might be the result of fluctuations in nutrient concentrations with the periodicity determined by the technical features of the MES. However, our (not presented) observations and experimentation on phosphate budgets have shown that at least this nutrient input was constant due to the high buffering capacity of the decomposer unit. Whatever the reasons, if the oscillation originates from mineralization and recirculation properties, the same might be said of the (irregular) fluctuation of algal populations in nature. In that case, the MES offers an opportunity for a systematic and experimental study of these driving forces.

It is thought that these kinds of micro-ecosystems can become a research tool in aquatic ecology. However, more and systematic research into the nature of the MES is needed.

Acknowledgements. Over the years many students have looked after the micro-ecosystem. All my colleagues in the laboratory (especially Dr. K. Kersting) who participated in the work and discussions on this subject are thanked. 


\section{LITERATURE CITED}

Grinten, P. M. E. M. van der \& Lenoir, J. M. H., 1973. Statistische procesbeheersing. Spectrum N. V., Utrecht, $599 \mathrm{pp}$.

Ringelberg, J. \& Kersting, K. Some notes on a new kind of aquatic micro-ecosystem. (In press.)

Sokal, R. R. \& Rohlf, F. J., 1969. Biometry. Freeman, San Francisco, 776 pp.

Taub, F. B., 1974. Closed ecological systems. A. Rev. Ecol. System. 5, 139-161.

Vandeginste, B. G. M., Salemink, P. J. M. \& Duinker, J. C., 1976. Auto- and crosscorrelograms of particulate trace metals in the Rhine estuary, Southern Bight and Dutch Wadden Sea. Neth. J. Sea Res. 10, 59-70.

Author's address: Dr. J. Ringelberg

Laboratory of Limnology

University of Amsterdam

Kruislaan 320

Amsterdam

The Netherlands 